\title{
POSITIVE ADAPTIVE RESPONSE OF WOMEN IN LOW SOCIO-ECONOMIC CLASS FOR CHANGE OF CONTRACEPTIVE METHOD FROM COMBINED CONTRACEPTIVE PILLS TO COPPER INTRAUTERINE DEVICE
}

\author{
Tehreem Yazdani, Nabila Amin*, Fareeha Zaheer*, Farhat Karim, Mohammad Saad Mukhtar**, Maryam Mukhtar*** \\ Combined Military Hospital Okara/National University of Medical Sciences (NUMS) Pakistan, *Pak Emirates Military Hospital/National University of Medical \\ Sciences (NUMS) Rawalpindi Pakistan, **Fazaia Medical College, Islamabad Pakistan, ***Rawalpindi Institute of Cardiology, Rawalpindi Pakistan
}

\section{ABSTRACT}

Objective: To ensure family spacing in our low socio-economic class.

Study Design: Quasi-experimental study.

Place and Duration of Study: Pak Emirates Military Hospital Rawalpindi, from Jan 2018 to Dec 2019.

Methodology: Two hundred females using oral contraceptive pills for spacing of children coming to Pak Emirates Military Hospital were selected. The problems of using contraceptive pills were identified. Out of these 87 women agreed to choose an intrauterine copper device (IUCD).

Results: Out of 200 women 87 converted from oral contraceptive pills to intrauterine copper device use. Most of them faced daily dosage problems $168(84 \%)$. Nausea was encountered by $123(61.5 \%)$ women and later settled in $89(44.5 \%)$ women. About $31(15.5 \%)$ were worried about the chances of uterine perforation and $56(28 \%)$ were worried about lost intrauterine copper device resulting in laparotomy. About $65(32.5 \%)$ were afraid of infection, backache and vaginal discharge. About 91 $(45.5 \%)$ women thought to have gastric problems with the intrauterine copper device. About $71(81 \%)$ agreed to have a spacing of children for about five years and removal whenever desired.

Conclusion: Intrauterine contraception is a very safe and efficient method for contraception as compared to oral pills. If expertise is, available it should be used and couples should be fully educated for its safety.

Keywords: Family planning, Intrauterine copper devices, Oral contraceptive pills.

How to Cite This Article: Yazdani T, Amin N, Zaheer F, Karim F, Mukhtar MS, Mukhtar M. Positive Adaptive Response of Women in Low SocioEconomic Class for Change of Contraceptive Method from Combined Contraceptive Pills to Copper Intrauterine Device. Pak Armed Forces Med J 2021; 71(5): 1585-1589. doi: https://doi.org/10.51253/pafmj.v71i5.4361

This is an Open Access article distributed under the terms of the Creative Commons Attribution License (https://creativecommons.org/licenses/by-nc/4.0/), which permits unrestricted use, distribution, and reproduction in any medium provided the original work is properly cited.

\section{INTRODUCTION}

More than 168 million women worldwide women use intrauterine devices (IUDs), and studies have shown that intrauterine copper devices have an efficacy of $99 \%$, especially in the first year of use ${ }^{1}$. From 2009 to 2012, the use of intrauterine copper devices has exponentially increased from $8.5-11.6 \%$ among women living in the United States ${ }^{2}$. In Pakistan, intrauterine copper devices are a very popular method of contraception owing to their convenience of use, easy discontinuation if required, and long term protection against pregnancy. Moreover, it is the second most popular contraceptive technique, with a $99.2-99.8 \%$ success rate within the first year of use ${ }^{3}$. Furthermore, the failure rate of intrauterine copper devices is only $0.8 \%$ at one year ${ }^{4}$. The use of intrauterine copper devices is unrelated to the patients' age, comorbidities, and does not depend on patient compliance ${ }^{5}$. They can be used effectively in the postpartum period and can work as an

Correspondence: Dr Tehreem Yazdani, HOD of Obstetrics \& Gynaecology, Combined Military Hospital, Okara Pakistan

Received: 29 May 2020; revision received: 20 Nov 2020; accepted: 27 Nov 2020 efficient contraceptive for emergency contraception ${ }^{6,7}$. Recently, due to a decrease in overall cost and proper counselling, studies prove that a large number of women choose intrauterine copper devices over contraceptive pills ${ }^{2}$. Moreover, oral contraceptives, patches and vaginal rings were linked to 20 times higher pregnancy rates than intrauterine copper devices ${ }^{8}$. Results from recent studies have shown a shift towards intrauterine copper devices among women of reproductive ages. They are even being recommended for use among sexually active teenagers in some countries, and easier access to these devices has been facilitated ${ }^{9,10}$. However, despite the advantages of intrauterine copper devices, women in some countries are still hesitant about using them. This might be a result of a lack of technical training of providers, concerns about adverse effects, especially infertility and infection. Another reason could be a lack of implementation of proper services to provide intrauterine copper devices ${ }^{10}$. An important concern among intrauterine copper devices users is the increased risk of pain and heavy menstrual bleeding, however, studies show that the frequency of 
these side effects decreases a few months after intrauterine copper device use ${ }^{8}$.

Another popular method of contraception is the use of oral contraceptive pills. However, oral contraceptive pills use has been linked to a large number of side effects. When the risk and benefits of intrauterine copper devices were compared with those of oral contraceptive pills, it was reported that oral contraceptive pills had a higher risk profile than intrauterine copper devices. The most harrowing issue involved with oral contraceptive pill use is patient compliance. Oral contraceptives pills have been linked to poor patient compliance leading to a high risk of contraception failure ${ }^{6}$. Imperfect use of oral contraceptive pills increases the risks of ovulation and in turn, increases the risk of unwanted pregnancy by $8 \%$ in 1 year ${ }^{10}$. As far as the side effects of oral contraceptive pills are concerned, the most common disadvantage reported was breakthrough vaginal bleeding. A study conducted by Archer et al reported that $18.5 \%$ of patients withdrew from the trial due to breakthrough bleeding ${ }^{10}$. However, another study reported improvement in the bleeding patterns with continuous use. Other side effects such as headaches, mood swings, bloating also seemed to improve with continuous use ${ }^{10}$. Other side effects of oral contraceptive pills reported in the literature are nausea, weight gain, and headaches. Oral contraceptive pills have also been reported to increase the risk of deep vein thrombosis (DVT), cholelithiasis, and increased risk of liver adenomas ${ }^{1}$. These side effects of oral contraceptive pills make intrauterine copper devices more favourable and efficient for the prevention of pregnancy. In this study, we have summarized the benefits of intrauterine copper devices over contraceptive pills as documented during our study.

\section{METHODOLOGY}

The quasi-experimental study on 200 females, at Pak Emirates Military Hospital was carried out from January 2018 to December 2019. Ethical Approval was obtained by the Institutional Review Board (IRB No. A/28/EC/ 86).

Inclusion Criteria: Females using combined oral contraceptive pills.

Exclusion Criteria: Non-consenting females were excluded.

Most of them were from low socio-economic class and were using these pills for a period of six months to five years. Most of them were not living with their husbands as they were away due to army service requ- irements. They were asked about the problems during use of this method and issues were identified. Patient consent was obtained before commencing the study and patient confidentiality was ensured. Most of them reported being non-complaint to oral contraceptive pills. A number of side effects were faced by these women and nausea was mostly encountered side effect. They were also worried about vomiting, headache, weight gain, acne, abdominal distention and mood swings. Those who were uncomfortable with this method were educated for intrauterine copper devices. Out of these 200 women 87 were convinced and intrauterine copper devices was placed. Those who were not convinced were 113 and there were reasons for continuing of pills. The most common reason was that the husband comes home on planned vacation usually for few days to a month only in intervals, so continued contraception is not required. They were willing to continue pills in spite of side effects and problems. The use of pills was for short duration of about one or two months with interval of two to three months. The patients were followed up after six months. All the data was spread in the form of tables and calculations were made. Percentages were figured out. Data was analyzed by using SPSS-22 and student t-test was applied. The $p$-value was calculated and was found to be significant if $\leq 5$.

\section{RESULTS}

Out of 200 women, 87 were willing to change of family planning method from oral contraceptive pills to intrauterine copper devices (Table-I). There were

Table-I: Division of women for choice of method of contraception $(n=200)$.

\begin{tabular}{l|c}
\hline Method of Contraception & $\mathbf{n ~ ( \% )}$ \\
\hline Women continuing oral contraceptive pills & $113(56.5)$ \\
\hline Women adapted intrauterine copper devices & $87(43.5)$ \\
\hline
\end{tabular}

certain reasons for which they were using oral contraceptive pills but they also had certain reservations with its usage. The problem mostly faced was difficulty in regular usage which was $168(84 \%)$. Nausea was encountered by $123(61.5 \%)$ women and was later settled in $89(44.5 \%)$ of them. Similarly, vomiting was a problem with the usage of oral contraceptive pills in 40 $(20 \%)$ women. Headache, weight gain and abdominal distention was suffered by 61 (30.5\%), 44 (22\%) \& 22 $(16.5 \%)$ of women respectively. Acne was seen in 10 $(5 \%)$ of patients but it was bearable. There were a previous history of failed contraception with oral contraceptive pills in $29(14.5 \%)$ women. After the counselling session, $87(43.5 \%)$ women were convinced of the 
insertion of intrauterine copper devices and 113 $(56.5 \%)$ wished to continue with the preexisting method of contraception (Table-II).

Our patients were apprehensive about the use of intrauterine copper devices due to their reported side effects. Out of 200 women, 71 (35.5\%) were using oral contraceptive pills as they thought that intrauterine copper devices is a painful method. Similarly, 22 (11\%) were afraid of bleeding followed by the procedure and almost the same number were afraid of the chances of device expulsion. About 31 (15.5\%) were also worried about the chances of uterine perforation and 56 women were worried about lost intrauterine copper devices $(28 \%)$ resulting in laparotomy. Out of our patients, 65 $(32.5 \%)$ were afraid of infection, backache and vaginal discharge with the intrauterine device. Only 10 (5\%) of women knew about the local reaction of copper in uterine walls. Approximately 91 (45.5\%) of women were apprehensive of gastric problems following intrauterine copper devices use. A large number of women $131(65.5 \%)$ had the perception that intrauterine copper devices caused heavy menstrual blood flow leading to

Table-II: Problems faced by women with use of combined oral contraceptive pills $(n=200)$.

\begin{tabular}{l|c}
\hline Problems with Pills & $\begin{array}{c}\text { No. of Women Experiencing } \\
\text { the Problem (\%) }\end{array}$ \\
\hline Difficulty in Daily Dosage & $168(84)$ \\
\hline Nausea & $123(61.5)$ \\
\hline Nausea but settled later & $89(44.5)$ \\
\hline Vomiting & $40(20)$ \\
\hline Headache & $61(30.5)$ \\
\hline Weight Gain & $44(22)$ \\
\hline Abdominal Distention & $22(16.5)$ \\
\hline Acne & $10(5)$ \\
\hline $\begin{array}{l}\text { Previous failed oral } \\
\text { contraceptive pills }\end{array}$ & $29(14.5)$ \\
\hline
\end{tabular}

Table-III: Reasons to avoid intrauterine copper device $(n=200)$.

\begin{tabular}{l|c}
\hline $\begin{array}{l}\text { Fears to Avoid Intrauterine } \\
\text { Copper Device }\end{array}$ & $\begin{array}{c}\text { No. of Women Fearing of } \\
\text { Procedure due to Different } \\
\text { Reasons (\%) }\end{array}$ \\
\hline Painful Method & $71(35.5)$ \\
\hline Post procedure bleeding & $22(11)$ \\
\hline Chance of Expulsion & $21(10.5)$ \\
\hline $\begin{array}{l}\text { Chance of Uterine } \\
\text { perforation }\end{array}$ & $31(15.5)$ \\
\hline $\begin{array}{l}\text { Lost intrauterine copper } \\
\text { devices \& Laparotomy }\end{array}$ & $56(28)$ \\
\hline $\begin{array}{l}\text { Infection, Vaginal discharge, } \\
\text { Backache }\end{array}$ & $65(32.5)$ \\
\hline Local Copper Reaction & $10(5)$ \\
\hline Gastric Problems & $91(45.5)$ \\
\hline $\begin{array}{l}\text { Heavy Menstrual bleeding, } \\
\text { Weakness, Anaemia }\end{array}$ & $131(65.5)$ \\
\hline
\end{tabular}

weakness and anaemia (Table-III).

Despite the above-mentioned problems with the intra-uterine system, a large number of women switched to copper intrauterine copper devices. Furthermore, the side effects seen with oral contraceptive pill use such as vomiting, headache, weight gain, and abdominal distention were reported in a very small percentage of intrauterine copper devices users, with 69 $(79 \%)$ women reporting no side effects. Approximately $69(79 \%)$ patients reported that they were psychologically better after using intrauterine contraception (Table-IV).

Table-IV: Reasons to adapt and continue intrauterine copper device in follow-up ( $n=87)$.

\begin{tabular}{l|c}
\hline Reasons & Number of Women (\%) \\
\hline Better Compliance & $67(77)$ \\
\hline Easy Follow up & $55(63.2)$ \\
\hline Less chances of failure & $62(71)$ \\
\hline Spacing for 5 years at a stretch & $71(81)$ \\
\hline Easy removal when desired & $71(81)$ \\
\hline Lesser Side Effects & $69(79)$ \\
\hline Psychologically better & $69(79)$ \\
\hline
\end{tabular}

\section{DISCUSSION}

Despite the advantages of intrauterine copper devices, women in some countries are still hesitant about using them. This might be a result of a lack of technical training of providers, concerns about adverse effects, especially infertility and infection. Another reason could be a lack of implementation of proper services to provide intrauterine copper devices ${ }^{11,12}$. An important concern among intrauterine copper devices users is the increased risk of pain and heavy menstrual bleeding, however, studies show that the frequency of these side effects decreases a few months after intrauterine copper device use ${ }^{13}$.

Another popular method of contraception is the use of oral contraceptive pills (OCPs). However, oral contraceptive pill use has been linked to a large number of side effects. When the risk and benefits of intrauterine copper devices were compared with those of oral contraceptive pills, it was reported that oral contraceptive pills had a higher risk profile than intrauterine copper devices ${ }^{14}$. The most harrowing issue involved with oral contraceptive pill use is patient compliance. Oral contraceptive pills have been linked to poor patient compliance due to their imperfect use due to missed pills. Imperfect use of oral contraceptive pills increases the risks of ovulation and in turn, increases the risk of unwanted pregnancy by $8 \%$ in 1 year ${ }^{15}$. As far as the side effects of oral contraceptive pills are 
concerned, the most common disadvantage reported was breakthrough vaginal bleeding. A study conducted by Archer et al reported that $18.5 \%$ of patients withdrew from the trial due to breakthrough bleeding ${ }^{10}$. However, another study reported improvement in the bleeding patterns with continuous use $^{12}$. Other side effects such as headaches, mood swings, bloating also seemed to improve with continuous use. Oral contraceptive pills have also been reported to increase the risk of deep vein thrombosis (DVT), cholelithiasis, and increased risk of liver adenomas ${ }^{16,17}$. These side effects of oral contraceptive pills make intrauterine copper devices more favourable and efficient for the prevention of pregnancy.

The choice of method of contraception to suit a woman of low socio-economic class is a big challenge. Whatever method to be used, must be easy to adapt for the female. In our study, the focus is low socioeconomic class and most of the ladies of this class are multi-parous and less educated. They cannot abide by the regularity of oral contraceptive pills as was being done by most of the study population. The women using oral contraceptive pills had problems with its side effects such as nausea, vomiting, headache, bloating, weight gain and acne. They were not happy about its use as previously they had a failure with this method of contraception. In our study group, $43.3 \%$ of women agreed upon the effectiveness of intrauterine copper devices. There were different reasons for continuing oral contraceptive pills or switching to intrauterine copper devices. Those who continued oral contraceptive pills despite side effects and problems were due to that their husbands were Government Servants. They usually come home on planned vacations and for almost two to three weeks after two to three months. Therefore, they chose oral contraceptive pills as they thought that continued contraception is not needed for them.

The other group of patients adopted intrauterine copper devices for contraception. They wanted to have contraception without oral medicine and lesser side effects. This study population was very apprehensive about using intrauterine copper devices, especially about the painful procedure, post-procedure bleeding, heavy periods, risk of infection, and risk of a lost intrauterine copper device and need for laparotomy. They also had wrong ideas about gastric problems with this method. Those patients who had intrauterine copper devices placed showed good compliance after six months of follow-up, keeping in mind that it was a safe method, provided five years of contraception, and could be removed when desired.

A study conducted by Azmat et al in Pakistan showed the reasons for use of intrauterine copper devices and their discontinuation. It showed that women did not want to use intrauterine copper devices due to side effects like heavy menstrual bleeding, infection and gastric problems. The study reported a discontinuation rate of $526(18 \%)^{1}$. This study is comparable with our study as it showed the misconceptions and fears of women about the intrauterine device. However, our study reported better response with intrauterine copper devices, with $43 \%$ of women agreeing to intrauterine copper devices placement and $79 \%$ of women reporting psychological satisfaction with intrauterine copper devices to use.

A study conducted by Nelson et al, in the United States, showed new developments in the intrauterine device system and showed that more people preferred to use intrauterine devices over contraceptive pills. Furthermore, heavy menstrual bleeding reported with intrauterine device use was reported to decrease to $48 \%$ at 12 months follow up. Our study also reported lesser side effects with intrauterine copper device use as compared to OCP use in $79 \%$ of women ${ }^{2}$. The results from our study also show overall satisfaction with intrauterine copper device use, with $81 \%$ of individuals being satisfied with 5 year spacing of pregnancies.

In an article published by Yoost et al the benefits of using intrauterine devices were reported. It showed that intrauterine systems are safer, cheaper and easily available with lesser side effects ${ }^{5}$. It also reported an improvement in menorrhagia and dysmenorrhea. In our study, the same factors are discussed to choose intrauterine copper devices for choice of contraception in patients.

Birgisson NE and colleagues conducted a project for preventing unintended pregnancies in different groups. They showed that the method of choice of contraception should be adopted according to the situation and it should be effective to prevent unwanted pregnancy ${ }^{8}$. Folger SG and co-workers published Evidence-based guidance on Selected Practice Recommendations for contraception which showed the appropriate methods of choice for contraception in different scenicros ${ }^{18}$.

\section{LIMITATION OF STUDY}

There were several limitations to our study. Firstly, our studies carry all the limitations of a single centre retrospective analysis design. Secondly, the 
follow-up period was not adequate to assess compliance in patients using intrauterine copper devices. We were unable to account for the influence of residual unmeasured factors affecting the outcomes.

At the same time, however, to the best of our knowledge, our study is the first study done in Pakistan which reports a positive adaptive response towards intrauterine copper devices in women belonging to low socioeconomic class. This warrants a need for further studies to adopt an algorithm for suitable contraceptive methods according to patient needs.

\section{CONCLUSION}

Copper intrauterine copper devices are safe, cheap and commonly used methods of contraception with a lesser failure rate. If expertise is available, it should be a method of choice in the low socioeconomic group.

\section{Conflict of Interest: None.}

\section{Authors' Contribution}

TY: Conception, manuscript writing, NA: Design, FZ: Data analysis, FK: Supervision, validation, MSM: Manuscript writing, MM: Manuscript editing.

\section{REFERENCES}

1. Azmat SK, Shaikh BT, Hameed W, Bilgrami M, Mustafa G, Ali $\mathrm{M}$, et al. Rates of IUCD discontinuation and its associated factors among the clients of a social franchising network in Pakistan. BMC Women's Health 2012; 12(1): 8-12.

2. Nelson AL, Massoudi N. New developments in intrauterine device use: focus on the US. Open Access J Contracept 2016; 7(1): 127-132.

3. Ouyang M, Peng K, Botfield JR, McGeechan K. Intrauterine contraceptive device training and outcomes for healthcare providers in developed countries: A systematic review. PloS One 2019; 14(7): e0219746.

4. Harrison PF, Rosenfield A, editors. Contraceptive Research and Development: Looking to the Future. National Academies Press (US); 1996.

5. Yoost J. Understanding benefits and addressing misperceptions and barriers to intrauterine device access among populations in the United States. Patient Prefer Adherence 2014; 8(2): 947-952.
6. Curtis KM, Tepper NK, Jatlaoui TC, Berry-Bibee E, Horton LG, Zapata LB, et al. US medical eligibility criteria for contraceptive use, 2016. MMWR Recomm Rep 201; 65(3): 1-3.

7. Cleland K, Raymond EG, Westley E, Trussell J. Emergency contraception review: evidence-based recommendations for clinicians. Clin Obstet Gynecol 2014; 57(4): 741-745.

8. Birgisson NE, Zhao Q, Secura GM, Madden T, Peipert JF. Preventing unintended pregnancy: the contraceptive CHOICE project in review. J Women's Health 2015; 24(5): 349-53.

9. Jairaj S, Dayyala S. A cross-sectional study on acceptability and safety of IUCD among postpartum mothers at tertiary care hospital, Telangana. J Clin Diagn Res 2016; 10(1): LC01-LC05.

10. Archer DF, Jensen JT, Johnson JV, Borisute H, Grubb GS. Evaluation of a continuous regimen of levonor-gestrel/Ethinyl estradiol: phase 3 study results. Contracept 2006; 74(6): 439-445.

11. Jain S, Vaid NB, Narang Y. A randomised controlled trial comparing the efficacy and side-effects of the intravaginal ring (Nuvaring $\left.{ }^{\circledR}\right)$ with combined oral hormonal preparation in dysfunctional uterine bleeding. J Clin Diagn Res 2016; 10(3): QC21.

12. Blumenthal PD, Chakraborty NM, Prager S, Gupta P, Lerma K, Vwalika B. Programmatic experience of post-partum IUD use in Zambia: an observational study on continuation and satisfaction. Eur J Contracept Reprod Health Care 2016; 21(5): 356-360.

13. Chowdhury ME, Women AY, Shiblee SI, Alam MM, Rahman MN. Acceptability, side-effects and discontinuation of second and third-generation oral contraceptive pills in Bangladesh: A quasi-experimental study. Available at: https://www. Researchsquare.com/article/rs-47147/v1 (Accessed on Dec 15, 2019)

14. Edelman A, Micks E, Gallo MF, Jensen JT, Grimes DA. Continuous or extended cycle vs. cyclic use of combined hormonal contraceptives for contraception. Cochrane Database Syst Rev 2014; 2014(7): CD004695.

15. Espey E, Ogburn T. Perpetuating negative attitudes about the intrauterine device: textbooks lag behind the evidence. Contracept 2002; 65(6): 389-395.

16. Khatri B, Khadka A, Amatya A, Shrestha SM, Paudel R. Perception and use of intrauterine contraceptive devices (iucd) among married women of reproductive age in bhaktapur, Nepal. Open Access J Contracept 2019; 10(1): 69-77.

17. Hooda R, Mann S, Nanda S, Gupta A, More H, Bhutani J. Immediate postpartum intrauterine contraceptive device insertions in caesarean and vaginal deliveries: a comparative study of follow-up outcomes. Int J Reprod Med 2016; 2016(2): 7695847.

18. Folger SG, Jamieson DJ, Godfrey EM. Evidence-based guidance on selected practice recommendations for contraceptive use: identification of research gaps. Contracep 2013; 87(5): 517-521. 